\title{
A randomized controlled trial investigating the effect of Pycnogenol and Bacopa CDRI08 herbal medicines on cognitive, cardiovascular, and biochemical functioning in cognitively healthy elderly people: the Australian Research Council Longevity Intervention (ARCLI) study protocol (ANZCTR12611000487910)
}

Con K Stough ${ }^{1 *}$, Matthew P Pase ${ }^{1}$, Vanessa Cropley², Stephen Myers ${ }^{3}$, Karen Nolidin ${ }^{1}$, Rebecca King ${ }^{1}$, David Camfield ${ }^{1}$, Keith Wesnes ${ }^{1,4}$, Andrew Pipingas ${ }^{1}$, Kevin $\mathrm{Croft}^{5}$, Dennis Chang ${ }^{6}$ and Andrew B Scholey ${ }^{1}$

\begin{abstract}
Background: One of the major challenges associated with our ageing population is the increasing incidence of age-associated cognitive decline, which has significant implications for an individual's ability to lead a productive and fulfilling life. In pure economic terms the costs of ageing reflects decreased productivity and engagement with the workforce. The maintenance of brain health underpinning intact cognition is a key factor to maintaining a positive, engaged, and productive lifestyle. In light of this, the role of diet, including supplementation with nutritional and even pharmacological interventions capable of ameliorating the neurocognitive changes that occur with age constitute vital areas of research.

Methods: In order to reduce cognitive ageing, the ARC longevity intervention (ARCLI) was developed to examine the effects of two promising natural pharmacologically active supplements on cognitive performance. ARCLI is a randomized, placebo-controlled, double-blind, 3-arm clinical trial in which 465 participants will be randomized to receive an extract of Bacopa monnieri (CDRI08 300 mg/day), Pycnogenol (150 mg/day), or placebo daily for 12 months. Participants will be tested at baseline and then at 3, 6 and 12 months post-randomization on a wide battery of cognitive, neuropsychological and mood measures, cardiovascular (brachial and aortic systolic and diastolic blood pressures as well as arterial stiffness), biochemical (assays to measure inflammation, oxidative stress and safety) as well as genetic assessments (telomere length and several Single Nucleotide Polymorphisms). The primary aim is to investigate the effects of these supplements on cognitive performance. The secondary aims are to explore the time-course of cognitive enhancement as well as potential cardiovascular and biochemical mechanisms underpinning cognitive enhancement over the 12 months of administration.

ARCLI will represent one of the largest and most comprehensive experimental clinical trials in which supplements are administered to elderly participants. Results from ARCLI may help develop novel preventative health practices and nutritional/pharmacological targets in the elderly for cognitive and brain health.
\end{abstract}

\footnotetext{
* Correspondence: cstough@swin.edu.au

'Centre for Human Psychopharmacology, Swinburne University of

Technology, Melbourne, Australia

Full list of author information is available at the end of the article
} 


\section{Background and Rationale}

With increasing life expectancies and the maturation of the "baby boom" generation, adapting to the challenges posed by the ageing population has been identified as one of the major issues facing contemporary society [1]. Human ageing has significant societal, economic, health and, importantly, personal costs. In pure economic terms the costs of ageing reflects decreased productivity as well as increased levels of reliance on public services for health and social support but this also has obvious ramifications for older people's ability to lead fulfilling lives. Increasing age is associated with a cluster of illnesses many involving oxidative stress and low level chronic inflammation. These include cardiovascular and respiratory disease and, importantly neurological conditions such as Parkinson's disease (PD) and Alzheimer's disease (AD).

\section{What is Cognitive Ageing?}

Individual age-related changes in cognition vary greatly. However research in cognitive aspects of ageing (typically in 60 to 90 year-olds) has identified consistent deficits in: reasoning and decision making; spatial abilities; perceptual-motor and cognitive speed; and most robustly memory (e.g. [2]). Longitudinal studies of aged populations illuminate the time-course of cognitive deterioration. Using 5 to 10 year re-test intervals significant decrements across most cognitive capacities become evident. A recent review of longitudinal ageing studies concludes that crystallized intelligence (e.g., factual knowledge) remains intact until late ageing whereas measures of speed, information processing and aspects of memory (e.g., working memory) are more sensitive to decline from age 60 [2].

\section{Brain Ageing and Oxidative Stress}

Neuroimaging studies reveal that increasing age is reliably associated with ventricular enlargement, reduction in gross brain volume, reductions in frontal and temporo-parietal brain volume, higher levels of cortical atrophy, and increased white matter hyperintensities [3]. Ultimately, shrinkage of cortical volume reduces cognitive capacity [4] and age-related increases in neuropathological events such as beta-amyloid protein deposition and formation of neurofibrillary tangles represent significant risk factors for cognitive decline and AD. Neuropathological events such as beta-amyloid deposition are not exclusive to neurodegenerative disorders such as $\mathrm{AD}$, in fact occurring in a large proportion of cognitively intact individuals. For example, in one study the proportion of non-clinical subjects with betaamyloid deposits ranged from $3 \%$ in a $36-40$ age group to $75 \%$ in a $85+$ age group [5].

Alongside age-associated cortical degeneration [4], there exist numerous microscopic insults related to oxidative stress and free radical damage. Free radicals are molecules with unpaired electrons. These molecules are highly unstable and can cause damage to proteins, lipids, carbohydrates and nucleotides [6]. Free radicals formed in the brain produce significant cellular damage, and mediate processes which result in neural cell death on large scales [7]. Between $95 \%$ and $98 \%$ of free radicals and Reactive Oxygen Species (ROS) $\left(\mathrm{O}_{2}{ }^{\circ}, \mathrm{HO}^{\circ}, \mathrm{H}_{2} \mathrm{O}_{2}\right)$ are formed by mitochondria as by-products of cellular respiration. Studies of mitochondria isolated from the brain show that $2-5 \%$ of total oxygen consumed yields ROS [8], these highly reactive molecules make a significant contribution to the peroxidation of principal cell structures (e.g. membrane lipids) [8]. Brain tissue is particularly susceptible due to it's disproportionately high metabolic rate and levels of oxygen, the cytotoxic actions of glutamate, and it's high concentrations of peroxidisable unsaturated fatty acids [7]. Ageing decreases the brain's ability to combat the actions of free radicals and is associated with increased levels of pro-oxidant mediators and decreased antioxidant levels [9]. The relationship between cognition and oxidative stress is evident in the extensive damage caused by free radicals in agerelated neurological conditions $[10,11]$, and animal models of age-related oxidative injury with central cognitive and behavioural impairments [12]. Concurrent with the normal age-related cognitive changes are increases in the formation of brain ROS resulting in significant damage to DNA, proteins and in particular membrane lipids [13]. Although multiple factors precipitate oxidative stress throughout the body, the brain is particularly vulnerable and its cumulative effects may account for the delayed onset and progressive nature of Alzheimer's and Parkinson's dementias, as well as normal age-related mental deterioration [10].

\section{Antioxidants and Cognition}

The central role of oxidative stress in age-related cognitive decline and neurodegenerative diseases has driven numerous studies examining the potential benefits of antioxidants in altering, reversing, or forestalling neuronal and behavioural changes (e.g. [14]). Anti-oxidant supplementation results in improved cognition and 
behaviour in aged animals and concurrent decreases in oxidative insult to neural structures [15]. Human research in this area is largely limited to epidemiological studies. These have identified positive associations in aged individuals between biological levels of dietary antioxidants (vitamins $\mathrm{E}$ and $\mathrm{C}$ ) and working memory measures including the Wechsler Memory test [16]. Less reliable than biological measures, large scale studies (3000+ participants) have also identified positive relationships between dietary intake of vitamin $\mathrm{C}$ and $\mathrm{E}$ and standardized memory measures [17]. While these nonclinical trials do not demonstrate causality, the consensus that memory is the main cognitive variable affected by antioxidant status is consistent with patterns of agerelated cognitive decline and the in vivo neuroanatomy of lipid peroxidation [18].

Given the consequences of a burgeoning ageing population, the role of supplementation with nutritional and pharmacological interventions capable of ameliorating the neurocognitive changes that occur with age constitute vital areas of research.

\section{Treatments to Reduce or Ameliorate Brain Ageing}

(i) Pycnogenol Neural cells have three systems of protection and repair in response to oxidative stress; 1) Enzymatic antioxidants (superoxide dismutase, catalase, peroxidases); 2) Radical scavenging lipid-soluble (tocopherols, flavonoids, carotenoids) and water-soluble (ascorbate, glutathione) antioxidants; and 3) repair proteases and phospholipases [7]. Pycnogenol ${ }^{\circledR}$ is a patented concentrate consisting of condensed flavonoids isolated from Maritime Pine bark. Extensive reviews by Packer et al [19] and Rohdewald [20] have established the antioxidant activity of Pycnogenol in simplified assay systems, cultured cell models, and perfused organs. There is evidence that Pycnogenol prolongs the lifetime of the ascorbate antioxidant and stimulates the synthesis of antioxidant enzymes inside arterial cells [21]. The established neuroprotective properties of flavonoids strongly advocate their use in intervention strategies [22]. Of these, Pycnogenol is particularly promising, having been studied extensively in the context of protecting against oxidative damage to specific neural systems. Kobayashi [23] reported that Pycnogenol had neuroprotective properties in HT-4 neuronal cells subjected to glutamateinduced cytotoxicity (one of the principle sources of ROS in the brain [10]. Similarly Liu [24] and Peng [25] found Pycnogenol to inhibit beta-amyloid apoptosis of neurons and vascular cells, both of which are oxidative processes that accumulate with age, and are pathological features of AD. In vivo supplementation to aged animals [26] results in biological and behavioural changes consistent with the slowing of age-related decline in physiology, learning and memory. Additionally $6 \mathrm{wk}$ Pycnogenol supplementation to humans resulted in significantly reduced serum low density lipoprotein and increased plasma oxygen radical absorbance capacity (ORAC) [27] - a convenient although non-specific measure of in vivo antioxidant activity [28].

(ii) Bacopa Monniera (L.) Wettst. (syn. Bacopa monniera Hayata \& Matsum) has been used in traditional Ayurvedic medicine for various indications including memory decline, inflammation, pain, pyrexia, epilepsy and as a sedative [29]. Bacopa contains Bacoside A and Bacoside $B$ which are steroidal saponins believed to be essential for the clinical efficacy of the product. While Bacopa has been reported to have many actions, its memory enhancing effects have attracted most attention and are supported by the psychopharmacology literature. Behavioural studies in animals have shown that Bacopa improves motor learning, acquisition and retention, and delay extinction of newly acquired behaviour [30]. Although the exact mechanisms of action remain uncertain, evidence suggests that Bacopa may modulate the cholinergic system and/or have antioxidant and metal chelating effects [31,32]. Bacopa may also have anti inflammatory [33], anxiolytic and antidepressant actions $[34,35]$, relaxant properties in blood vessels [36] and adaptogenic activity [37]. Chronic administration of Bacopa inhibits lipid peroxidation in the prefrontal cortex, striatum and hippocampus via a similar mechanism to vitamin E [38]. In an animal model of $\mathrm{AD}$, there was a dose-related reversal by Bacopa of cognitive deficits produced by the neurotoxins colchicine and ibotenic acid [32]. In rodents, Bacopa inhibited the damage induced by high concentrations of nitric oxide in astrocytes [39]. Memory deficits following cholinergic blockade by scopolamine were reversed by Bacopa treatment. In animal studies Bacopa reduced lipid peroxidation induced by $\mathrm{FeSO}_{4}$ and cumene hydroperoxide indicating that, similarly to the chelating properties of EDTA, it acts at the initiation level by chelating $\mathrm{Fe}^{++}[40]$. More recently in transgenic mice, Bacopa supplementation reduced specific amyloid peptides by up to $60 \%$ whilst also improving memory performance [41]. Thus, Bacopa appears to have multiple modes of action in the brain all of which may be useful in ameliorating cognitive decline in the elderly. These include: (i) direct pro-cholinergic action; (ii) anti-oxidant (flavonoid) activity; (iii) metal chelation; (iv) anti-inflammatory effects; (v) improved blood circulation; (vi) adaptogenic activity; and (vii) removal of $\beta$-amyloid deposits. In contrast to anti-oxidants such as Vitamin $\mathrm{C}$ and $\mathrm{E}$, and specific anti-oxidants such as Pycnogenol, the polypharmacological actions of Bacopa potentially act on several pathological changes in elderly brains in concert. This potential is supported by a limited number of clinical trials into the neurocognitive effects of Pycnogenol and, to a greater extent, Bacopa. Both substances are capable of improving memory functioning in 
cognitively intact cohorts, with Pycnogenol improving working memory [42] and Bacopa preferentially enhancing secondary memory (reviewed in Pase et al.[43]). In both cases effects are evident at three months of daily administration, but not earlier.

\section{Design and methodology Design}

ARCLI is a randomized, double-blind, placebo-controlled, 3-arm parallel-groups clinical trial with participants randomized to receive Bacopa, Pycnogenol or a placebo.

\section{Aims and study hypotheses}

Extending upon preliminary findings $[42,44,45]$, the primary aim of the current study is to examine the individual chronic 12 month effects of Bacopa (300 mg daily), and Pycnogenol (150 mg daily) on cognitive performance in a healthy elderly population. The secondary aims of the current study are two fold. Firstly, to investigate the time course of cognitive ehancement with follow-up testing at 3, 6 and 12 months. Secondly, to examine putative mechanisms underpinning any cognitive enhancing actions of the supplements by examining relationships between cognitive, biological (biochemical and genetic) and cardiovascular variables over the 12 months. By examining the interrelationship between inflammation, oxidative stress, cardiovascular health and cognitive perfromance, the current study aims to identify modifiable risk factors for cognitive decline that can be targeted by supplementation. It is hypothesized that all supplements will improve measures of cognitive performance, relative to placebo, at all time points with the greatest cognitive effects observed at 12 months.

\section{Centres}

ARCLI will be conducted at the Centre for Human Psychopharmacology, Swinburne University, Melbourne, Australia. In the first year approximately $1 / 3$ of the cohort will be enrolled. In years 2 and 3 additional recruitment will occur at the University of Western Sydney (Sydney, Australia).

\section{Participants}

A total of 465 healthy, elderly participants aged between 60 and 75 years will take part in the study. This restricted age range was chosen due to the large variation in cognitive abilities and trajectories associated with ageing. Participants will be randomized to receive one of three daily treatments for 12 months: (a) $300 \mathrm{mg}$ Bacopa (KeenMind CDRI 08 extract); (b) 150 mg Pycnogenol; or (c) placebo. Participants will be excluded from participation if they are a current smoker; have a psychiatric or neurological disease; significant endocrine, gastrointestinal or cardiovascular disorder; other disorder affecting food metabolism; recent history (past 5 years) of chronic/severe illness (longer than 6 weeks); current regular alcohol use exceeding 14 standard drinks per week for women and 28 standard drinks per week for men; vision that is not corrected to normal. To be eligible, participants cannot be taking psychoactive medication including, antidepressants, antipsychotics, anxiolytics, cholinesterase inhibitors, illicit drugs or significant cognitive enhancing drugs (e.g. chronic intake of substances such as Ginkgo). Participants who are irregular users of vitamin or herbal supplements will be asked to stop taking them for the duration of the trial. Participants who are regular users (defined as daily intake for greater than 3 months) of vitamins or herbal supplements will be asked to maintain the same habits throughout the trial. Participants with either global cognitive impairment or significant levels of depressive symptoms, as determined by a score $<24$ on the Mini Mental State Examination (MMSE) or a score $>19$ on the Geriatric Depression Scale respectively, will be excluded. To ensure that participants do not have probable dementia, those scoring between 24-26 on the MMSE will be administered the Dementia Rating Scale II (DRS-II). Any questionable cases on the DRS-II will be discussed by the ARCLI participant safety committee for agreement on eligibility. The study was ethically approved by the Swinburne University Human Research Ethics Committee (project number 2010/106) and all participants will provide written informed consent. The trial has been registered with the Australian and New Zealand Clinical Trials Registry (ACTRN12611000487910).

\section{Procedure}

Eligible participants are required to attend five testing session. An overview of the testing sessions is provided in the clinical trial flow chart (Figure 1). During the first session, participants are screened for eligibility and a detailed history is taken. Eligible participants are then asked to give blood and to complete the cognitive test batteries multiple times. This allows the participant to familiarize themselves with the cognitive tasks and minimises practice effects (as well as establishing that the participant lies within established norms for their age group). Cognitive data obtained during the training visit will not be included in statistical analysis. Visit 2 involves baseline assessment of all measures and randomization to treatment. Participants are to commence taking their assigned treatment on the day following their baseline assessment. As depicted in Figure 1, visits 3 to 5 involve follow-up assessment at 3, 6 and 12 months post randomization. At the 12 month assessment, participants will be asked to return any remaining supplements, such that they can be counted enabling the investigators to estimate compliance to treatment. 


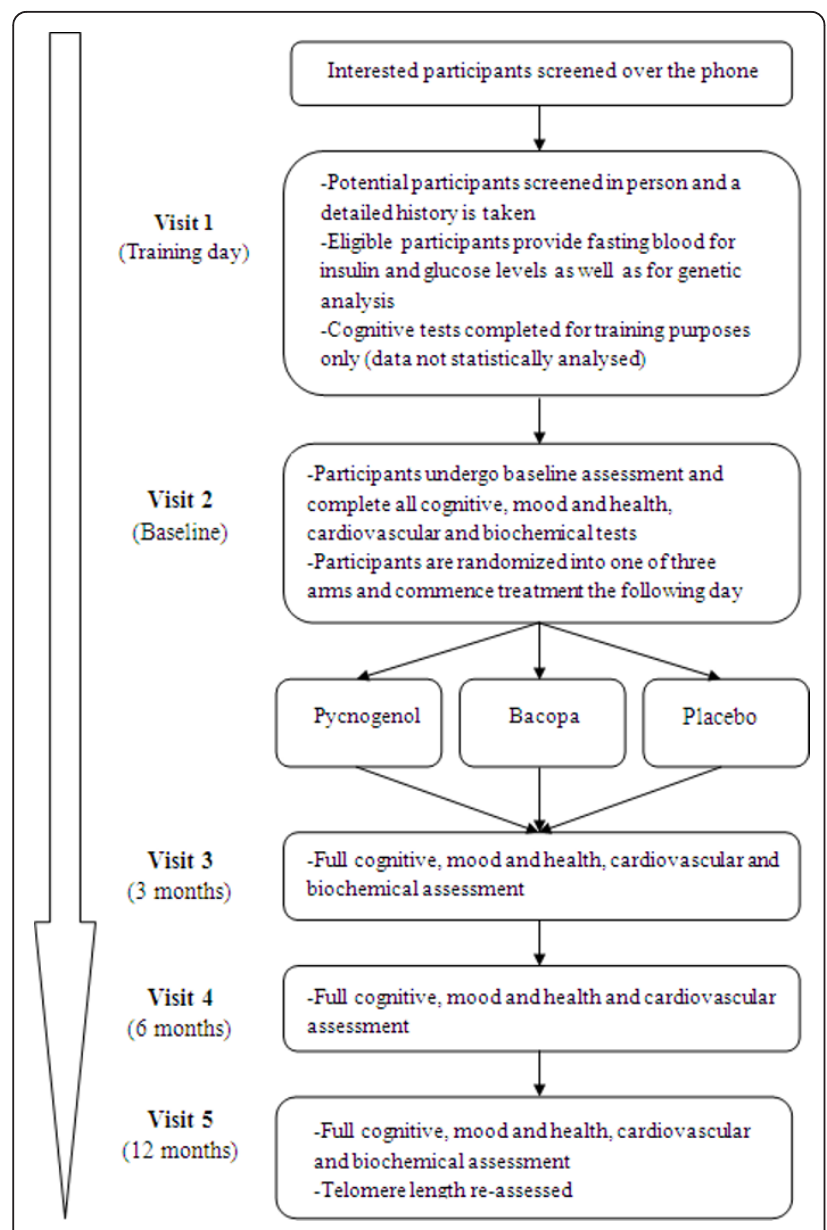

Figure 1 ARCLI protocol flow diagram.

\section{Sample size}

The sample size for this study is 465 participants with 155 participants in each arm. Previous studies using Bacopa and Pycnogenol have reported statistical significance on measures of cognition with approximately 100 participants in each of these studies respectively $[42,44]$. Based on these previous studies, the current sample size of 465 ensures adequate power to detect a significant effect $80 \%$ of the time when conducting two-tailed tests using $95 \%$ confidence even when allowing for a $10-20 \%$ attrition rate.

\section{Treatments}

(a) The Bacopa supplement used in ARCLI is an extract of Bacopa monnieri called CDRI08 and is commercially available as KeenMind ${ }^{\mathrm{TM}}$ (Flordis). This product is manufactured from the stems, leaves and roots of Bacopa and is extracted with $50 \%$ ethanol. It is standardized to contain active bacosides at levels of $55 \% \pm 5 \%$. This extract has previously been shown to enhance cognitive performance at this dosage after 3 months of supplementation $[44,45]$.

(b) Pycnogenol (Horphag Research, Geneva, Switzerland) is a patent extract made exclusively from the bark of French maritime pine trees (Pinus pinaster). Pycnogenol contains consistent proportions of bioflavonoids and is standardized to contain $70 \pm 5 \%$ procyanidins. This dosage of Pycnogenol has previously been shown to enhance memory performance after 3 months of supplementation [42].

\section{Randomization and safety}

An independent researcher (Medical practitioner) located at an independent university will be responsible for the randomization of the study treatments and will chair the safety committee. Participants will be randomly assigned to one of the three treatment groups according to a Latin square design. Randomization codes will be kept in a sealed opaque envelope in a secure safe and will only be opened in case of emergency.

\section{Primary outcome}

The primary study outcome is the effect of supplementation on cognitive performance as measured by a battery of well validated and highly sensitive cognitive tests. These tests will be implemented at baseline and all follow-up time points (3, 6 and 12 months post baseline). This battery will include all tasks from the Cognitive Drug Research (CDR) Computerized Assessment System and selected tasks from the Swinburne University Computerized Cognitive Assessment Battery (SUCCAB). Table 1 lists the cognitive measures assessed by the CDR and SUCCAB batteries. Wechsler intelligence (Wechsler Abbreviated Scale of Inteligence-WASI) will also be administered as both an estimate of pre-morbid intelligence as well as a factor to determine whether IQ predicts response to any of the supplements.

The CDR battery has been used in well over 1000 clinical trials world wide, is well validated, and has been shown to be sensitive to the effects of several natural supplements including Bacopa and Pycnogenol [42,44]. The SUCCAB is sensitive to the effects of age-associated cognitive decline and has been recommended for use when assesing cognitive changes following nutraceutical supplementation [46]. The SUCCAB has also been shown sensitive to the effects of a pine bark extract similar to Pycnogenol [47]. Both the CDR and SUCCAB provide detailed assessments of memory performance (both short and long term), a domain of cognition expected to be modulated by treatment. The cognitive demand battery [48] will be implemented to assess the effects of supplementation on cognitive effort and fatigue whilst the MMSE [49] will be used as a dementia screening tool at intake and to monitor the effects of treatment on global cognitive decline (after randomization). The Inspection Time task [50] and Hick Reaction Time paradigm [51] 
Table 1 Cognitive domains measured by CDR and SUCCAB tests

\begin{tabular}{llll}
\hline CDR & SUCCAB & Hick RT & Inspection Time \\
\hline Simple RT & Stroop Colour-Word & Simple Decision Time & Perceptual Speed \\
Choice RT & Spatial Working Memory & Simple Movement Time & 2 Choice Decision Time \\
Spatial WM & Contextual Memory & 2 Choice Movement Time \\
Numeric WM & Immediate/Delayed Recognition & 4 Choice Decision Time \\
Picture Presentation & & 4 Choice Movement Time \\
Immediate Word Recall & & 8 Choice Decision Time \\
Digit Vigilance & & 8 Choice Movement Time \\
Delayed Word Recall & & \\
Word Recognition & & \\
Picture Recognition & & \\
Rapid Visual Information Processing & & \\
\hline
\end{tabular}

$\mathrm{CDR}=$ Cognitive Drug Research, SUCCAB = Swinburne University Computerized Cognitive Assessment Battery, RT = Reaction Time, WM = Working Memory

will be used as they provide highly valid and sensitive assessment of mental speed which has been shown to slow with increasing age.

\section{Secondary outcomes}

A wide range of psychological, cardiovascular, biochemical and genetic measures will also be collected at different time points as part of ARCLI. These are described below and listed in Table 2 .

\section{Mood, health and dietary habits}

Numerous self-report questionnaires will be used to assess mood and general health. Depressive symptoms and state-trait anxiety will be measured with the Beck Depression Inventory II (BDI-II) [52] and the Spielberger State-Trait Anxiety Inventory [53] respectively. Further assessment of mood will be performed with the
Profile of Mood Scales [54] and the Bond and Lader Visual Analogue Scales [55]. Throughout the trial, general health, fatigue and sleep quality will be assessed with the General Health Questionnaire [56], Chalder Fatigue Scale [57] and the Leeds Sleep Evaluation Questionnaire [58] respectively. Dietary habits will be inferred from an in-house Food Frequency Questionnaire.

\section{Cardiovascular}

Brachial pressures, aortic pressures and carotid-femoral Pulse Wave Velocity (PWV) are not only associated with cardiovascular disease risk and mortality $[59,60]$ but also cognitive performance and decline $[61,62]$. These variables can all be modified by diet and lifestyle changes [63-65] and will therefore be monitored throughout the trial as one possible mechanism by which the study supplements improve brain function. Brachial blood pressure

Table 2 Summary of the secondary outcomes implemented in ARCLI across all time points

\begin{tabular}{|c|c|c|c|c|c|}
\hline & Training & Baseline & 3 month & 6 month & 12 month \\
\hline Screening & $\begin{array}{l}\text { Medical history \& screen } \\
\text { (GDS, MMSE, DRS-II) } \\
\text { Demographic Q }\end{array}$ & $\begin{array}{l}\text { Medical screen (ie BMI, } \\
\text { MMSE, medication use) }\end{array}$ & $\begin{array}{l}\text { Medical screen (ie BMI, } \\
\text { MMSE, medication use) }\end{array}$ & $\begin{array}{l}\text { Medical screen (ie BMI, } \\
\text { MMSE, medication use) }\end{array}$ & $\begin{array}{l}\text { Medical screen (ie BMI, } \\
\text { MMSE, medication use) }\end{array}$ \\
\hline Biochemical & $\begin{array}{l}\text { Fasting Glucose \& } \\
\text { Insulin* } \\
\text { APOE \& SNP }\end{array}$ & $\begin{array}{l}\text { F2 Isoprostanes } \\
\text { Cytokines* \& CRP } \\
\text { MBA } \\
\text { Telomere length }\end{array}$ & $\begin{array}{l}\text { F2 isoprostanes } \\
\text { Cytokines* \& CRP } \\
\text { MBA }\end{array}$ & - & $\begin{array}{l}\text { F2 isoprostanes } \\
\text { Cytokines* \& CRP } \\
\text { MBA } \\
\text { Telomere length }\end{array}$ \\
\hline Cardiovascular & - & $\begin{array}{l}\text { Brachial BP } \\
\text { Aortic BP } \\
\text { carotid-femoral PWV }\end{array}$ & $\begin{array}{l}\text { Brachial BP } \\
\text { Aortic BP } \\
\text { carotid-femoral PWV }\end{array}$ & $\begin{array}{l}\text { Brachial BP } \\
\text { Aortic BP } \\
\text { carotid-femoral PWV }\end{array}$ & $\begin{array}{l}\text { Brachial BP } \\
\text { Aortic BP } \\
\text { carotid-femoral PW }\end{array}$ \\
\hline Health & $\begin{array}{l}\text { FFQ } \\
\text { Chalder Fatigue } \\
\text { Leeds Sleep evaluation } \\
\text { Trait anxiety }\end{array}$ & $\begin{array}{l}\text { General Health Q } \\
\text { State anxiety } \\
\text { Leeds Sleep Evaluation } \\
\text { BDI-II } \\
\text { POMS }\end{array}$ & $\begin{array}{l}\text { General Health Q } \\
\text { State anxiety } \\
\text { Leeds Sleep Evaluation } \\
\text { BDI-II }\end{array}$ & $\begin{array}{l}\text { General Health Q } \\
\text { State anxiety } \\
\text { Leeds Sleep Evaluation } \\
\text { BDI-II }\end{array}$ & $\begin{array}{l}\text { FFQ } \\
\text { General Health Q } \\
\text { State anxiety } \\
\text { Leeds Sleep Evaluation } \\
\text { BDI-II }\end{array}$ \\
\hline Other & $\begin{array}{l}\text { NEO PI-R } \\
\text { WASI }\end{array}$ & & & & Estimate of compliance \\
\hline
\end{tabular}

* = Analysis performed for morning participants only

GDS = Geriatric Depression Scale, MMSE = Mini Mental State Examination, DRS = Mattis Dementia Rating Scale, Q = Questionnaire, APOE = Apolipoprotein E, SNP = Single Nucleotide Polymorphisms, WASI = Wechsler Abbreviated Scale of Intelligence FFQ = Food Frequency Questionnaire, NEO PI-R = NEO Personality-Inventory Revised, POMS $=$ Profile of Mood States, BMI = Body Mass Index, CRP $=$ C Reactive Protein, MBA $=$ Multiple Blood Analysis, BP $=$ Blood Pressure, PWV $=$ Pulse Wave Velocity 
will be measured after a 5 minute rest period using a clinically validated automated sphygmomanometer. Applanation tonometry of the radial artery will be used to estimate aortic pressures and wave reflections using a non-invasive SphygmoCor device. The same SphygmoCor device will be used to measure PWV through applanation of the carotid and femoral arteries. In addition to this assessment, cerebral and common carotid blood flow velocity and endothelial dependent vasodilation of the brachial artery may be measured on a subset of participants using transcranial Doppler and flow mediated dilation respectively.

\section{Biochemical}

Pre-randomization, one off biochemical assessment will be conducted to measure glycated haemoglobin (HbA1c) and insulin levels. Measurement of blood glucose and insulin will provide a measure of baseline glucoregulatory efficiency and control, which may contribute to age-related cognitive decline [66]. At both baseline and selected follow-up time points, biochemical markers of oxidative stress, inflammation and safety profiling will be measured through high sensitivity C-Reactive Protein, F2-Isoprostanes, inflammatory cytokines (e.g. TNF- $\alpha$, IL-2, IL-4, IL-6, IL-10 \& IFN-gamma) and Liver Function Tests.

\section{Genetic}

Blood collected pre-randomization will also be used to assess a platform of Single Nucleotide Polymorphisms thought to be related to cognitive/brain function, general health or response to treatment. This will include assessment of the APOE4 allele, which is associated with an increased risk of $\mathrm{AD}$ [67] and cognitive decline in normal elderly [68] but also more than 100 targeted polymorphisms including BDNF, cytokines amongst others. Genotyping will allow investigation of whether certain polymorphisms affect response to treatment or show differential relationships with the cognitive and biological variables. Telomere length (a marker of genetic damage) will also be assessed at baseline and 12 months to investigate whether any of the treatments modulate telomere shortening over the duration of the study.

\section{Analysis}

The primary analysis will investigate the effects of treatment on all cognitive outcomes over the course of the study using Analysis of Variance (ANOVA) techniques. Other more powerful statistical techniques such as linear mixed modelling and intention to treat analysis will be considered. Similar statistical techniques will be used to investigate the effects of treatment on the secondary outcomes. Pearson's correlation coefficients will be used to investigate whether any improvements in cognition are related to improvements in other variables of interest such as biochemical, cardiovascular or mood/health factors. Correlations and regression models may be used to examine baseline associations between variables. Results will be considered statistically significant at $\mathrm{p}<$ 0.05 corrected for multiple cognitive factors (primary outcome variables) or $\mathrm{p}<.05$ for secondary outcome variables.

Covariates such as age, gender and baseline cognitive screening measures (e.g., MMSE and Wechsler intelligence) will be adjusted for in the analyses. Results will be presented as appropriate effect sizes with a measure of precision (95\% confidence intervals). Compliance to treatment will be analysed by counting each participants remaining supplements once they have completed the trial.

\section{Safety and Data Monitoring Committee}

A data and safety committee will comprise the study GP (Prof Myers), the study nurse, the Chief Investigator (Prof Stough) and a medical officer attached to the Centre for Human Psychopharmacology but not otherwise part of ARCLI.

\section{Conclusions}

Given our currently ageing population, research addressing the issue of cognitive decline in aged individuals is critical. This issue is further reinforced by the fact that such cognitive decline frequently precedes various forms of dementia. The proposed study will be the largest and most definitive yet assessing the role of the cognitive enhancers Bacopa and Pycnogenol on combined cognitive and biological measures in elderly participants. Improving the cognitive functioning of elderly citizens will have significant benefits at the societal, economic and personal levels. Cognitive capacity is strongly correlated with performance in many occupations and ameliorating the decline in fluid intelligence, memory and reasoning will allow many elderly people to continue to work and to continue to contribute to our society as they age. Coupled with the large sample size, ARCLI is one of the most definitive studies to explore the effects of Bacopa and Pycnogenol on cognitive ageing. Results from this study may help guide policies and preventative health practices in the elderly.

\footnotetext{
Abbreviations

AD: Alzheimer's Disease; ANOVA: Analysis of Variance; APOE: Apolipoprotein E; ANZCTR: Australia and New Zealand Clinical trials Registry; ARCLI:

Australian Research Council Longevity Intervention; BMI: Body Mass Index; BP: Blood Pressure; CDR: Cognitive Drug Research; CRP: C Reactive Protein; DRS: Mattis Dementia Rating Scale; FFQ: Food Frequency Questionnaire; GDS: Geriatric Depression Scale; IQ: Intelligence Quotient; MBA: Multiple Blood Analysis; MMSE: Mini Mental State Examination; NEO PI-R: NEO
} 
Personality-Inventory Revised; POMS: Profile of Mood States; PWV: Pulse Wave Velocity; Q: Questionnaire; RCT: Randomized, Controlled Trial; ROS: Reactive Oxygen Species; RT: Reaction Time; SNP: Single Nucleotide Polymorphisms; SUCCAB: Swinburne University Computerized Cognitive Assessment battery; WASI: Wechsler Abbreviated Scale of Intelligence; WM: Working Memory.

\section{Acknowledgements}

The study is funded by an Australian Research Council Discovery grant to Prof Stough, Scholey and Croft with co-funding from Horphag and Flordis who are providing the Pycnogenol and Bacopa respectively. Mr. Pase receives a Menzies Foundation Scholarship in Allied Health Sciences to work on the ARCLI trial.

\section{Author details}

${ }^{1}$ Centre for Human Psychopharmacology, Swinburne University of Technology, Melbourne, Australia. ${ }^{2}$ Melbourne Neuropsychiatry Centre, The University of Melbourne, Australia. ${ }^{3}$ Southern Cross University, Lismore, Australia. ${ }^{4} \mathrm{CDR}$, Bracket, Goring-On-Thames, England. ${ }^{5} \mathrm{~S} c h o o l$ of Medicine and Pharmacology, University of Western Australia, Australia. ${ }^{6}$ Complemed, NICM, University of Western Sydney, Australia.

\section{Authors' contributions}

CS and AS conceived the study. CS, AS and KC were applicants for funding All authors were involved in designing the study and drafting the protocol. All authors read and approved the final protocol.

\section{Competing interests}

The authors declare that they have no competing interests.

Received: 10 November 2011 Accepted: 6 March 2012

Published: 6 March 2012

\section{References}

1. Economic Implications of an Ageing Australia. Productivity Commission Research Report 2005

2. Christensen $\mathrm{H}$, Kumar R: Cognitive Changes and the Ageing Brain. In The Ageing Brain. Edited by: Sachdev PS. Lisse: Swets 2003:75-96.

3. Looi J, Sachdev PS: Structural Neuroimaging of the Ageing Brain. In The Ageing Brain. Edited by: Sachdev PS. Lisse: Swets 2003:49-62.

4. MacLullich AMJ, Ferguson KJ, Deary IJ, SeckI JR, Starr JM, Wardlaw JM: Intracranial capacity and brain volumes are associated with cognition in healthy elderly men. Neurology 2002, 59(2):169-174.

5. Braak H, Braak E: Frequency of stages of Alzheimer-related lesions in different age categories. Neurobiol Aging 1997, 18(4):351-357.

6. Slater TF: Free-radical mechanisms in tissue injury. Biochemical Journal 1984, 222(1):1-15.

7. Packer $L$ : Free radical scavengers and antioxidants in prophylaxy and treatment of brain diseases. In Free Radicals in the Brain. Edited by: Packer L, Prilipko L, Christen Y. New York. Springer-Verlag; 1992:.

8. Papa S, Skulachev VP: Reactive oxygen species, mitochondria, apoptosis and aging. Molecular and Cellular Biochemistry 1997, 174(1-2):305-319.

9. Artur Y, Herbeth B, Guémouri L, Lecomte E, Jeandel C, Siest G: Age-related variations of enzymatic defenses against free radicals and peroxides. EXS 1992, 62:359-367.

10. Coyle JT, Puttfarcken P: Oxidative stress, glutamate, and neurodegenerative disorders. Science 1993, 262(5134):689-695.

11. Smith MA, Perry G, Richey PL, Sayre LM, Anderson VE, Beal MF, Kowall N: Oxidative damage in Alzheimer's [6]. Nature 1996, 382(6587):120-121.

12. Forster MJ, Dubey A, Dawson KM, Stutts WA, Lal H, Sohal RS: Age-related losses of cognitive function and motor skills in mice are associated with oxidative protein damage in the brain. Proceedings of the National Academy of Sciences of the USA 1996, 93(10):4765-4769.

13. Smith CD, Carney JM, Starke-Reed PE, Oliver CN, Stadtman ER, Floyd RA Markesbery WR: Excess brain protein oxidation and enzyme dysfunction in normal aging and in Alzheimer disease. Proceedings of the National Academy of Sciences of the USA 1991, 88(23):10540-10543.

14. Sano M, Ernesto C, Thomas RG, Klauber MR, Schafer K, Grundman M, Woodbury P, Growdon J, Cotman CW, Pfeiffer E, Schneider LS, Thal LJ: A controlled trial of selegiline, alpha-tocopherol, or both as treatment for
Alzheimer's disease. New England Journal of Medicine 1997, 336(17):1216-1222

15. Socci DJ, Crandall BM, Arendash GW: Chronic antioxidant treatment improves the cognitive performance of aged rats. Brain Research 1995, 693(1-2):88-94.

16. Goodwin JS, Goodwin JM, Garry PJ: Association between nutritional status and cognitive functioning in a healthy elderly population. Journal of the American Medical Association 1983, 249(21):2917-2921.

17. Masaki KH, Losonczy KG, Izmirlian G, Foley DJ, Ross GW, Petrovitch $\mathrm{H}_{\text {, }}$ Havlik R, White LR: Association of vitamin E and C supplement use with cognitive function and dementia in elderly men. Neurology 2000, 54(6):1265-1272

18. Srám RJ, Binková B, Topinka J, Kotěsovec F, Fojtíková I, Hanel I, Klaschka J, Kocisóvá J, Prosek M, Machálek J: Effect of antioxidant supplementation in an elderly population. Basic life sciences 1993, 61:459-477.

19. Packer L, Rimbach G, Virgili F: Antioxidant activity and biologic properties of a procyanidin-rich extract from pine (pinus maritima) bark pycnogenol. Free Radical Biology and Medicine 1999, 27(5-6):704-724.

20. Rohdewald P: A review of the French maritime pine bark extract (Pycnogenol $^{\circledR}$ ), a herbal medication with a diverse clinical pharmacology. International Journal of Clinical Pharmacology and Therapeutics 2002, 40(4):158-168.

21. Wei ZH, Peng QL, Lau BHS: Pycnogenol enhances endothelial cell antioxidant defenses. Redox Report 1997, 3(4):219-224.

22. Ishige $K$, Schubert D, Sagara Y: Flavonoids protect neuronal cells from oxidative stress by three distinct mechanisms. Free Radical Biology and Medicine 2001, 30(4):433-446.

23. Kobayashi MS, Han D, Packer L: Antioxidants and herbal extracts protect HT-4 neuronal cells against glutamate-induced cytotoxicity. Free Radical Research 2000, 32(2):115-124

24. Liu F, Lau BHS, Peng Q, Shah V: Pycnogenol protects vascular endothelial cells from a-amyloid-induced injury. Biological and Pharmaceutical Bulletin 2000, 23(6):735-737.

25. Peng QL, Buz'Zard AR, Lau BHS: Pycnogenol ${ }^{\circledR}$ protects neurons from amyloid- $\beta$ peptide-induced apoptosis. Molecular Brain Research 2002, 104(1-2):55-65.

26. Liu FJ, Zhang YX, Lau BHS: Pycnogenol enhances immune and haemopoietic functions in senescence-accelerated mice. Cellular and Molecular Life Sciences 1998, 54(10):1168-1172.

27. Devaraj S, Vega-López S, Kaul N, Schönlau F, Rohdewald P, Jialal I: Supplementation with a pine bark extract rich in polyphenols increases plasma antioxidant capacity and alters the plasma lipoprotein profile. Lipids 2002, 37(10):931-934.

28. Prior RL, Cao G: In vivo total antioxidant capacity: Comparison of different analytical methods. Free Radical Biology and Medicine 1999, 27(11-12):1173-1181

29. Russo A, Borrelli F: Bacopa monniera, a reputed nootropic plant: An overview. Phytomedicine 2005, 12(4):305-317.

30. Singh HK, Dharwan BN: Neuropsychopharmacological effects of the Ayurvedic nootropic Bacopa monniera linn (Brahmi). Indian Journal of Pharmacology 1997, 29:S359-\$365.

31. Agrawal A: A comparative study of psychotropic drugs and bio-feedback therapy in the prevention and management of psychosomatic disorder. Thesis Varanasi: Banaras Hindu University; 1993.

32. Bhattacharya SK, Kumar A, Ghosal S: Effect of Bacopa monniera on animal models of Alzheimer's disease and perturbed central cholinergic markers of cognition in rats. Research Communications in Pharmacology and Toxicology 1999, 4(3\&4):1-12.

33. Jain SK: Ethnobotany and research on medicinal plants in India. Ciba Found Symp 1994, 185:153-164, discussion 164-158.

34. Bhattacharya S, Ghosal S: Anxiolytic activity of a standardized extract of Bacopa monniera: an experimental study. Phytomedicine 1998, 5(2):77-82

35. Sairam K, Dorababu M, Goel RK, Bhattacharya SK: Antidepressant activity of standardized extract of Bacopa monniera in experimental models of depression in rats. Phytomedicine 2002, 9(3):207-211.

36. Dar A, Channa S: Calcium antagonistic activity of Bacopa monniera on vascular and intestinal smooth muscles of rabbit and guinea-pig. $J$ Ethnopharmacol 1999, 66(2):167-174.

37. Rai D, Bhatia G, Palit G, Pal R, Singh S, Singh HK: Adaptogenic effect of Bacopa monniera (Brahmi). Pharmacol Biochem Behav 2003, 75(4):823-830. 
38. Bhattacharya SK, Bhattacharya A, Kumar A, Ghosal S: Antioxidant activity of Bacopa monniera in rat frontal cortex, striatum and hippocampus. Phytother Res 2000, 14(3):174-179.

39. Russo A, Borrelli F, Campisi A, Acquaviva R, Raciti G, Vanella A: Nitric oxiderelated toxicity in cultured astrocytes: effect of Bacopa monniera. Life Sci 2003, 73(12):1517-1526.

40. Tripathi YB, Chaurasia S, Tripathi E, Upadhyay A, Dubey GP: Bacopa monniera Linn. as an antioxidant: mechanism of action. Indian J Exp Biol 1996, 34(6):523-526.

41. Holcomb LA, Dhanasekaran M, Hitt AR, Young KA, Riggs M, Manyam BV: Bacopa monniera extract reduces amyloid levels in PSAPP mice. $J$ Alzheimers Dis 2006, 9(3):243-251.

42. Ryan J, Croft K, Mori T, Wesnes K, Spong J, Downey L, Kure C, Lloyd J, Stough C: An examination of the effects of the antioxidant Pycnogenol ${ }^{\circledR}$ on cognitive performance, serum lipid profile, endocrinological and oxidative stress biomarkers in an elderly population. Journal of Psychopharmacology 2008, 22(5):553-562.

43. Pase MP, Kean J, Sarris J, Neale C, Scholey AB, Stough C: The cognitive enhancing effects of Bacopa monneiri: $A$ systematic review of randomized, controlled human clinical trials. Journal of Alternative and Complementary Medicine.

44. Stough C, Downey LA, Lloyd J, Silber B, Redman S, Hutchison C, Wesnes K, Nathan PJ: Examining the nootropic effects of a special extract of Bacopa monniera on human cognitive functioning: 90 Day double-blind placebo-controlled randomized trial. Phytotherapy Research 2008, 22(12):1629-1634.

45. Stough C, Lloyd J, Clarke J, Downey LA, Hutchison CW, Rodgers T, Nathan PJ: The chronic effects of an extract of Bacopa monniera (Brahmi) on cognitive function in healthy human subjects. Psychopharmacology 2001, 156(4):481-484

46. Pipingas A, Harris E, Tournier E, King R, Kras M, Stough CK: Assessing the efficacy of nutraceutical interventions on cognitive functioning in the elderly. Current Topics in Nutraceutical Research 2010, 8(2-3):79-87.

47. Pipingas A, Silberstein RB, Vitetta L, Van Rooy C, Harris EV, Young JM, Frampton CM, Sali A, Nastasi J: Improved cognitive performance after dietary supplementation with a Pinus radiata bark extract formulation. Phytotherapy Research 2008, 22(9):1168-1174.

48. Scholey AB, French SJ, Morris PJ, Kennedy DO, Milne AL, Haskell CF: Consumption of cocoa flavanols results in acute improvements in mood and cognitive performance during sustained mental effort. Journal of Psychopharmacology 2010, 24(10):1505-1514.

49. Folstein MF, Folstein SE, McHugh PR: 'Mini mental state'. A practical method for grading the cognitive state of patients for the clinician. Journal of Psychiatric Research 1975, 12(3):189-198.

50. Deary IJ, Stough C: Intelligence and Inspection Time: Achievements, Prospects, and Problems. American Psychologist 1996, 51(6):599-608.

51. Jensen AR: The theory of intelligence and its measurement. Intelligence 2011, 39(4):171-177.

52. Beck AT, Ward CH, Mendelson M, Mock J, Erbaugh J: An inventory for measuring depression. Archives of general psychiatry 1961, 4:561-571.

53. Spielberger CD, Gorsuch RL, Lushene RE: Manual for the State-Trait Anxiety Inventory. Palo Alto California: Consulting Psychologists Press; 1970.

54. McNair DM, Lorr M, Droppelman LM: Profile of Mood States. San Diego: Educational and Industrial Testing Service; 1970

55. Bond A, Lader M: Use of analog scales in rating subjective feelings. British Journal of Medical Psychology 1974, 47:211-218

56. Goldberg D: General Health Questionnaire (GHQ-12). Windsor, England: NFER-Nelson; 1992.

57. Chalder T, Berelowitz G, Pawlikowska T, Watts L, Wessely S, Wright D, Wallace EP: Development of a fatigue scale. Journal of Psychosomatic Research 1993, 37(2):147-153.

58. Parrott $A C$, Hindmarch I: Factor analysis of a sleep evaluation questionnaire. Psychological Medicine 1978, 8(2):325-329.

59. Vlachopoulos C, Aznaouridis K, O'Rourke MF, Safar ME, Baou K, Stefanadis C: Prediction of cardiovascular events and all-cause mortality with central haemodynamics: A systematic review and meta-analysis. European Heart Journal 2010, 31(15):1865-1871.

60. Vlachopoulos C, Aznaouridis K, Stefanadis C: Prediction of Cardiovascular Events and All-Cause Mortality With Arterial Stiffness. A Systematic Review and Meta-Analysis. Journal of the American College of Cardiology 2010, 55(13):1318-1327.
61. Pase MP, Pipingas A, Kras M, Nolidin K, Gibbs AL, Wesnes KA, Scholey AB, Stough C: Healthy middle-aged individuals are vulnerable to cognitive deficits as a result of increased arterial stiffness. Journal of Hypertension 2010, 28(8):1724-1729.

62. Pase MP, Herbert A, Grima NA, Pipingas A, O' Rourke MF: Arterial stiffness as a cause of cognitive decline and dementia: A systematic review and meta-analysis. Internal Medicine Journal.

63. Pase MP, Grima NA, Sarris J: The effects of dietary and nutrient interventions on arterial stiffness: a systematic review. American Journal of Clinical Nutrition 2011, 93(446-454).

64. Tanaka $\mathrm{H}$, Safar ME: Influence of lifestyle modification on arterial stiffness and wave reflections. American Journal of Hypertension 2005, 18(1):137-144.

65. Pase MP, Grima NA, Sarris J: Do long-chain $n-3$ fatty acids reduce arterial stiffness? A meta-analysis of randomised controlled trials. British Journal of Nutrition 2011, 106(07):974-980.

66. Messier C, Tsiakas M, Gagnon M, Desrochers A, Awad N: Effect of age and glucoregulation on cognitive performance. Neurobiology of Aging 2003, 24(7):985-1003.

67. Saunders AM, Strittmatter WJ, Schmechel D, St. George-Hyslop PH, PericakVance MA, Joo SH, Rosi BL, Gusella JF, Crapper-MacLachlan DR, Alberts MJ, Hulette C, Crain B, Goldgaber D, Roses AD: Association of apolipoprotein E allele $\varepsilon 4$ with late-onset familial and sporadic Alzheimer's disease. Neurology 1993, 43(8):1467-1472.

68. Dik MG, Jonker C, Comijs HC, Bouter LM, Twisk JWR, Van Kamp GJ, Deeg DJH: Memory complaints and APOE- $\varepsilon 4$ accelerate cognitive decline in cognitively normal elderly. Neurology 2001, 57(12):2217-2222.

doi:10.1186/1475-2891-11-11

Cite this article as: Stough et al:: A randomized controlled trial investigating the effect of Pycnogenol and Bacopa CDRI08 herbal medicines on cognitive, cardiovascular, and biochemical functioning in cognitively healthy elderly people: the Australian Research Council Longevity Intervention (ARCLI) study protocol (ANZCTR12611000487910). Nutrition Journal 2012 11:11.

\section{Submit your next manuscript to BioMed Central and take full advantage of:}

- Convenient online submission

- Thorough peer review

- No space constraints or color figure charges

- Immediate publication on acceptance

- Inclusion in PubMed, CAS, Scopus and Google Scholar

- Research which is freely available for redistribution

Submit your manuscript at www.biomedcentral.com/submit
C Biomed Central 